\title{
Managing and Analyzing the Constructive and Functional Parameters on Fiberglass Custom Sensor Design for an Aerodynamic Balance
}

\author{
RADU CALIN PAHONIE ${ }^{1}$, AMADO STEFAN ${ }^{1}$, CARMEN LUIZA COSTULEANU²*, DANIEL BOLDUREANU³, \\ GABRIELA GLADIOLA ANDRUSEAC ${ }^{3}$ \\ 1Military Technical Academy, 39-49 George Cosbuc Blvd., Bucharest, Romania \\ 2Ion Ionescu de la Brad University of Agricultural Sciences and Veterinary Medicine of lasi, Department of Agrobusiness, \\ 3 Mihail Sadoveanu Alley, 700490, Iasi, Romania \\ ${ }^{3}$ Grigore T. Popa University of Medicine and Pharmacy lasi, Romania, Department of Biomedical Science, 16 Universitatii Str., \\ 700115, lasi, Romania
}

\begin{abstract}
An external three component strain gauge balance, designed, analyzed and manufactured in the Military Technical Academy is presented. The balance is a multi-piece type and employs the use of six custommade load cells (sensors) to transfer the aerodynamic forces and moments from the wing to the computer software environment for data processing and analysis. The relations between the loads acting on the wing model and the measured forces are also underlined. The placement of the strain gauge on the composite laminate is an important issue for increased sensor precision; therefore, it is given a thorough analysis. The positioning of the force vector and its influence on the strain distribution over the lift sensor is also numerically and experimentally analyzed.
\end{abstract}

Keywords: aerodynamic balance, composite material, fiberglass, strain gauge, managing and analyzing

The lightweight wings are the key aerodynamic elements in designing efficientlightair-vehicles, and nowadays a shiftin research towards flexible liftsurfaces is visible [1]. An important step towards developing the lightweight, flexible wing of a small aircraft is assessing the quality of the geometrical, structural alterations one performs upon a classical wing type [2]. To be able to evaluate the benefits and make fair comparisons, one needs to use an external aerodynamic balance with both wings types, traditional and innovative, placed under the same conditions in a low-speed wing tunnel, and perform accurate measurements [3].

This paper challenges the obstacles in custom designing an extemal aerodynamic balance for wing aerodynamic small loads data collection by custom made composite strip sensors. The particular set of circumstances for which the external balance is designed consists mainly of three interest areas: the low-speed aerodynamics, small loads (10-50N) and flexible surfaces on an asymmetric wing.

An external balance for wind tunnel experiments can be defined from a structural point of view, as an elastic device supporting the experimental model, created to measure the aerodynamic loads acting on the model, as described in [4]. The primary function of the balance is to decompose the aerodynamic load in some components (between three and six), which can be measured individually with high precision. There are already in use countless aerodynamic balances, each with its particularities and design, customized for specific or general needs [1].

The external balance design philosophy is based on mechanical decoupling of forces [5]. The measurement of loads on the six active components allows obtaining the forces and moments components needed for wing study and comparison. From a theoretical point of view, this design concept does not focus on the coupling effects between the three forces components and moments. Nevertheless, some coupling effects are expected among the measured loads.
Those effects can be introduced by a lot of factors, such as improper assembly of balance components, deformation of the model supports, deformation of the active balance components, and so on.

A correctcalibration procedure compensates for the errors introduced by the coupling of forces, but it also considers the magnitude of the error. Stressing the importance of the calibration, the force coupling effect becomes critical in the relation between lift and drag. For example, for high-quality balances the error introduced by the coupling effects in the measurements is only about $1 \%$ but for aeronautical applications, this is also the order of ratio between lift and drag.

\section{Experimental part}

Methods and materials

The external aerodynamic balances Data Acquisition System (DAQS) is composed of several elements that allow the conversion of physical forces into digital values. The entire measuring system is highly influenced by each and any of its components; therefore, a brief look into the DAQSis considered mandatory.

The following subsystems compose the DAQS:

\section{Mechanical device}

This element has to ensure there are no frictional forces present and, by doing so, there are no undesired loads measured. The geometry of the mechanical device is shown in figure 1, and the main structural components are highlighted.

\section{Custom strain gauge sensors}

This active component that converts the physical load into an electric signal is highly dependent on the quality of the pressure sensors, strain gauges or base material type. The load cells, also known as strain gauges, are commonly used to generate electrical signals through the mechanical 


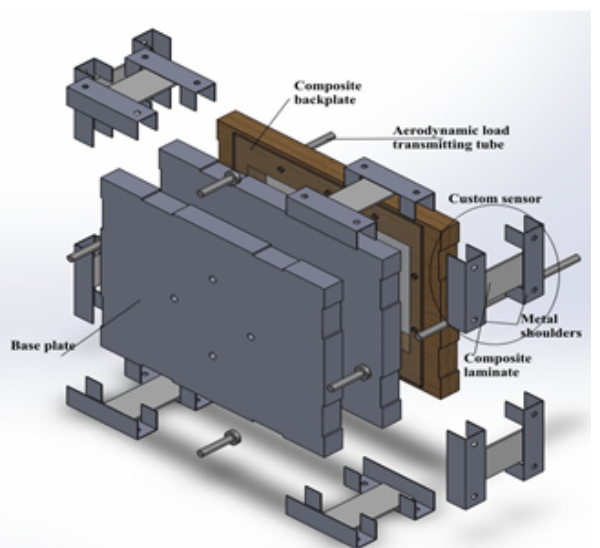

Fig. 1. Geometrical design for mechanical support device

deformation caused by the applied force. In this particular sensor system design a pair of constantan foil resistance, strain gauges, of $349.8 \pm 0.1 \mathrm{mV}$ resistance each was used on both sides of a six layer-fiberglass composite strip, as shown in fig. 1, 2 and 3. Four strain gauges were mounted coplanar, on two composite strips, to form a Wheatstone bridge and convert the deformation into an electrical signal.

\section{Electronic amplifiers}

Having the sensor output signal as a weak millivoltsignal, the role of the amplifier comes naturally to increase the power of the signal to a distinct signal for the analog to digital converter used. Therefore, six 0 5V (10V)/4 20mA load cell sensor amplifiers were used for the full bridge strain gauge force transducers. One is depicted in fig. 3 .

\section{Wires}

The quality and efficiency of the wires that carry the signal between the sensor and the amplifier cannot be stressed enough, so low resistance high-quality electric wires were used.

\section{Data acquisition module}

This type of device performs conversions of a continuous analog signal into a discrete time digital signal. The parameters that differentiate between these acquisition modules are resolution, sampling rate and accuracy. The converter used (NI USB-6210) in the measuring system with a resolution of 16 bits, eight channels and a sampling rate of $250 \mathrm{kS} / \mathrm{s}$ is deemed appropriate for wind tunnel balance requirements by [2]. Also, the level of integration with computers is very high, and the user can build his software.

\section{Software}

The software applications that post process the acquired data to obtain the forces and moments values needed are available in several options: from commercial applications to custom designed ones, from calculus sheets to complex codes modeled on the complexity of the wind tunnels.

\section{Strain gauge placement through CAD analysis}

Placing the strain gauges on the composite strips was done after the entire external balance was modeled in a CAD environment and the correct length of the composite strips was determined. In the open CAD environment, the whole balance model was drawn and statically analyzed using the finite element method [6]. To simulate the deformation of the composite strips, the parts were drawn to size, and the material models were chosen accordingly.
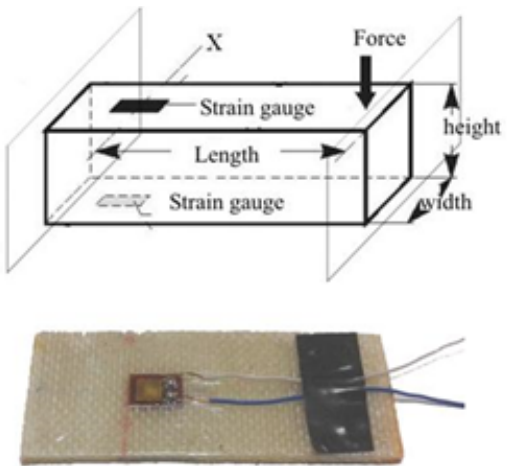

Fig. 3. Strain gauge sensor on composite strip- top view

The meshing was done using tetrahedral 8 node elements under the Simulation module of the CAD [7]. On the surfaces corresponding to the strain gauge placement, the mesh was refined with an element edge constraint of $0.4 \mathrm{~mm}$. The total number of nodes generated was 413881 with about 268000 items (fig. 4).

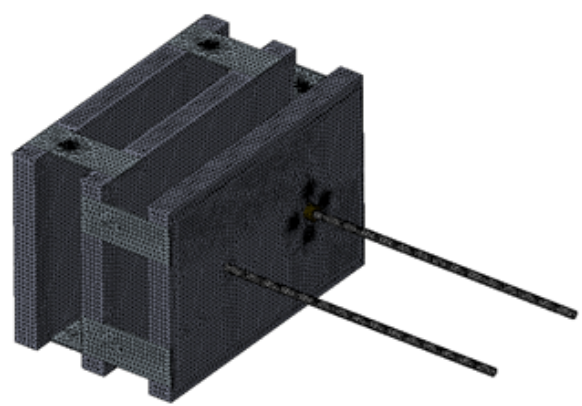

Fig. 4. The finite element model's made mesh with 413881nodes and 268143 tetra elements

In the measurement problem on hand, strain gauges have been used, one on each side of the composite strip, sensors connected in a full bridge Wheatstone configuration. The composite strip acts as a bending beam under the loads introduced on one end by the moving fixture frame.

It is well known that the arms of the Wheatstone bridge are formed by the strain gauges active grid resistors. The connections between the transducers and the instruments were color coded according to the HBM standard. Then these insulated black and blue wires connect to nodes 2 and 3 and introduce a known excitation voltage UE. The output voltage UA that appears between nodes 1 and 4 linked to the white and red wires depends on the ratio of resistors R1: R2 and R4: R3.

In general, the equation:

$$
\frac{U_{A}}{U_{E}}=\frac{R_{1}}{R_{1}+R_{2}}-\frac{R_{4}}{R_{3}+R_{4}}=\frac{R_{1} R_{3}-R_{2} R_{4}}{\left(R_{1}+R_{2}\right)\left(R_{3}+R_{4}\right)}
$$

is valid, and for the balanced bridge case we can write:

$$
\frac{U_{A}}{U_{E}}=0
$$

After the bridge is detuned and UA appears we can write:

$$
\frac{U_{A}}{U_{E}}=\frac{1}{4}\left(\frac{\Delta R_{1}}{R_{1}}-\frac{\Delta R_{2}}{R_{2}}+\frac{\Delta R_{3}}{R_{3}}-\frac{\Delta R_{4}}{R_{4}}\right)
$$

moreover, substituting we have:

$$
\frac{U_{A}}{U_{E}}=\frac{k}{4}\left(\varepsilon_{1}-\varepsilon_{2}+\varepsilon_{3}-\varepsilon_{4}\right)
$$

The fixed gauge factor $k$ is determined after the calibration with dead weights.

For a bending beam [8], the conditions are straightforward and favorable because the strain values 
for the Wheatstone bridge configuration are of the same absolute value but opposite signs.

For the composite strip sensors study involving the variation of the particular strain along its length, to precisely position the pressure gauge, its finite element model was analyzed. The surfaces on each end of the strip that are connected to the frames of the aerodynamic balance are modeled to having imposed displacements (as in fig. 5). When a force is applied to the tubes, the balance's frames move in such a way that they remain in a parallel position to each other. In consequence, the nodal displacements corresponding to the nodes in section A were blocked, whereas the displacements of the nodes in section $B$ had a tolerance of $0.1 \mathrm{~mm}$ in the normal direction of the composite strip.

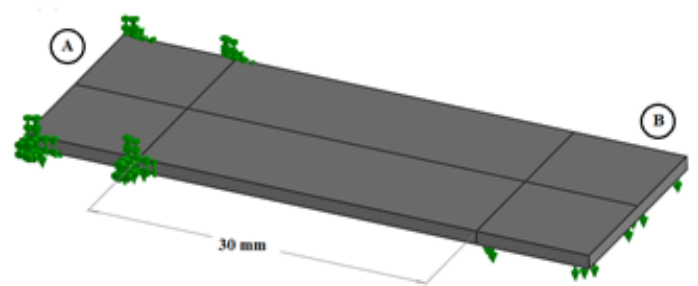

Fig. 5. Composite strip modeled geometry and boundary conditions. A-Fixed Displacements, B- Imposed displacements of $0.1 \mathrm{~mm}$

\section{Results and discussions}

Following the analysis of the obtained results of strain distribution over the composite strip in a typical loading case scenario, we can see an almost constant stress distribution over the width of the strip (fig. 6).

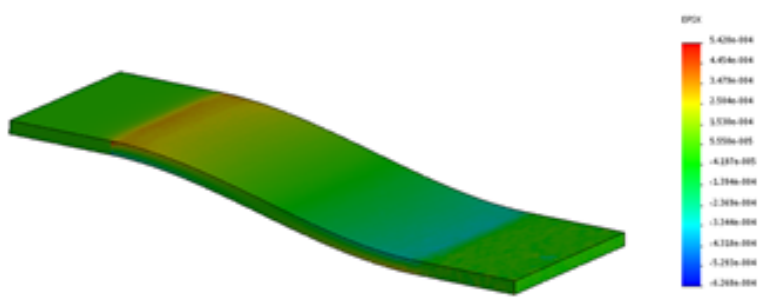

Fig. 6. Strain along the composite strip (in the gauge's direction)

A grip effect is also present, but it is of little consequence because it does not affect the central area of the strip. Along the length of the strip, on its upper surface, the strains vary from positive values (positive towards $A$ section) to negative values (towards the $B$ sections the composite fibers in the strip are subjected to compression). This process is mirrored on the lower surface of the composite strip with the fibers closer to section $A$ being compressed.

Therefore, the strains measured by the gauges on the upper side of the strip are the same as the ones measured on the underside but of different signs. The conditions become better when adding the values in the equation (4).

Figure 7 shows the variation of the strain on the upper surface of the composite strip, where the strain gauge is positioned, in the axis direction. We can see that the maximum values are not present at the end of the piece, as the bent beam theory $[8,9]$ would suggest, but at a distance of approximately $0.68 \mathrm{~mm}$ away.

Averaging the stress values obtained in the Mathcad software [10], over a $4 \mathrm{~mm}$ length that corresponds to the active length of the strain gauge, for different placement distances of the strain gauge from the section $A$ (the edge of the frame) we have plotted the graph in figure 8. One can notice that the strain gauge positioned right atthe edge of the frame leads to the maximum strain value, therefore to the maximum sensor effectiveness.

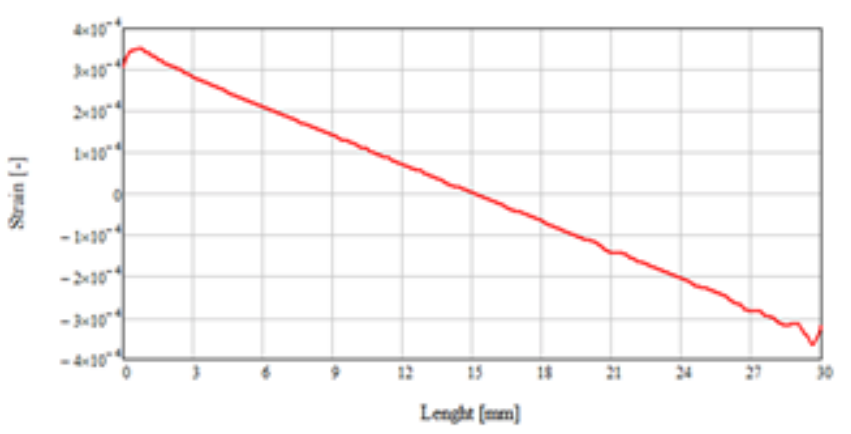

Fig.7. Strain over the length of strip

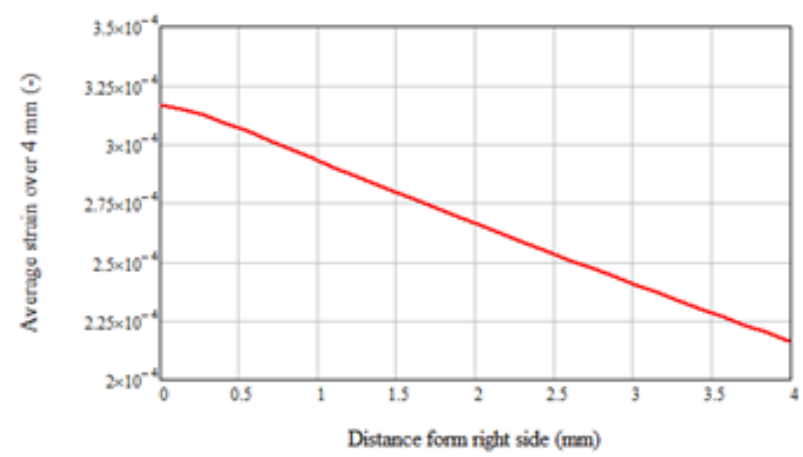

Fig. 8. Strain variation averaged over the active length of the strain gauge with the distance to the frame edge (section A)

The alignment marks of the strain gauges have been lined up with the middle of the composite strip with a placement distance of $16 \mathrm{~mm}$ from one end of the strip (fig. 3). This way strain gauges were positioned one on each side of the composite strip, the positioning distances to the composite strips end being checked beforehand to ensure a perfect symmetry and superposition of the two strain gages.

A positioning system was used for more precision [1113]. Therefore, we obtained a mirror like configuration and the doubling of strain gauge measurement precision. Bonding the strain gauges on the composite strips was done with an adhesive based on a cyanoacrylate compound that does not affect the gauges wiring. The connection wires were put in place after the glue was completely dry, and their isolation was done with a thin single component silicone rubber without any solvents.

Positioning the force vector and its influence on the strain distribution over the lift sensor

This influence has been analyzed by loading one of the forces introducing tubes of the aerodynamic balance so that only the lift force corresponding composite strips are active and then varying the position of the force over the tube. Ten different distances or position of the normal force vector have been considered, one for every $10 \mathrm{~mm}$, starting from the edge of the frame. Figure 9 and 10 show the stresses and strains, for all the mounted strain gauges under the $10 \mathrm{~N}$ introduced force.

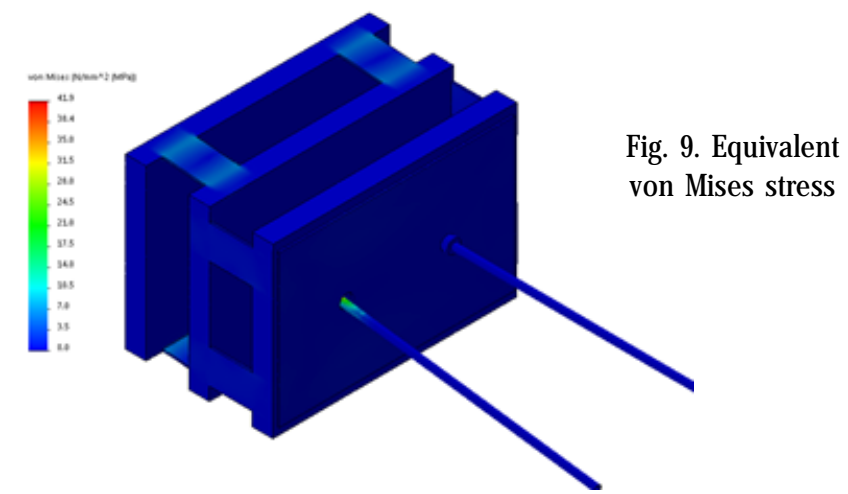




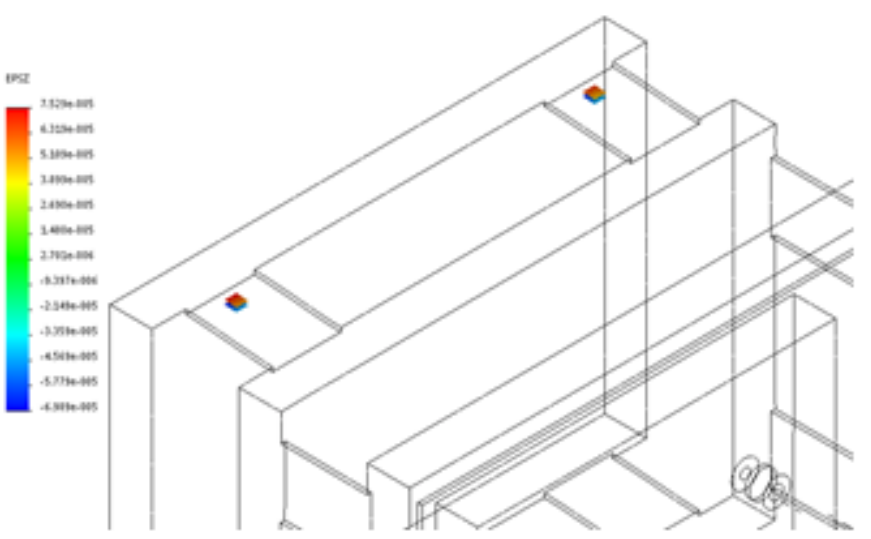

Fig. 10. Strain on the surface of the strain gauges under the $10 \mathrm{~N}$ loading of the aerodynamic balance

For every loading case, the strains are computed over the gauges' directions. Considering the following relation between the measured force and strain:

$$
F_{\text {Lift }}=K_{\varepsilon}\left(\varepsilon_{1}-\varepsilon_{2}+\varepsilon_{3}-\varepsilon_{4}\right)
$$

where $K_{e}$ is a constant determined after the first loading scenario and $\varepsilon_{i}$, with $i=1,2,3,4$ are the strains corresponding to the sensor gauge, we can see a theoretical influence of the force vector placement position over the measured value (fig. 11).

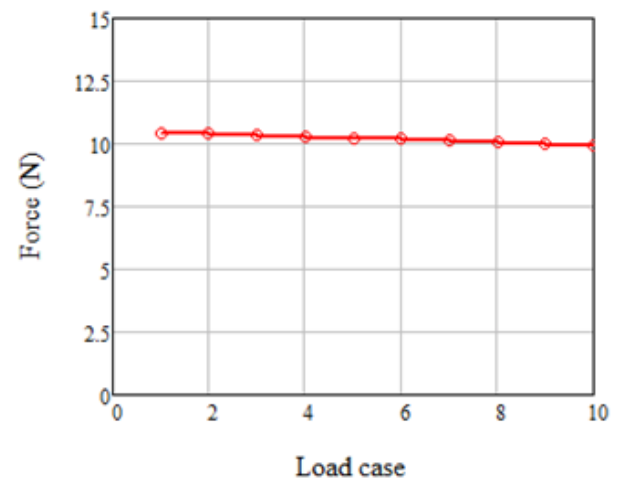

Fig. 11. Theoretical (FEM method) variation of the lift force, measured by the sensor, with the distance to the force vector

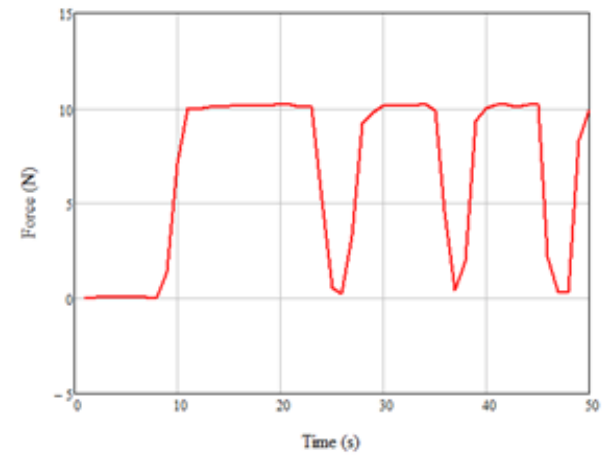

Fig. 12. Experimental variation of the lift force as measured by the sensor, with the placement of the force vector

The force vector positioning error between the highest and lowest distances to the sensor is about $4.6 \%$.

The experimental determination of this variation of the force with its placement position has been done in four points by placing a weight of a $1000 \mathrm{~g}$ on one of the loading tubes. Figure 12 presents this variation. A suitable sensor measurement behavior can be seen and the measured value being insignificantly influenced by the force vector placement (under 1\%).

The results and observations made can be extended to the composite strips corresponding to the sensors that measure the resistance force, the basic design being the same [14-16].

The loading of the balance with a force that induces only the lift leads to strains in the sensors corresponding to the resistance force, as can be seen in figure 13.

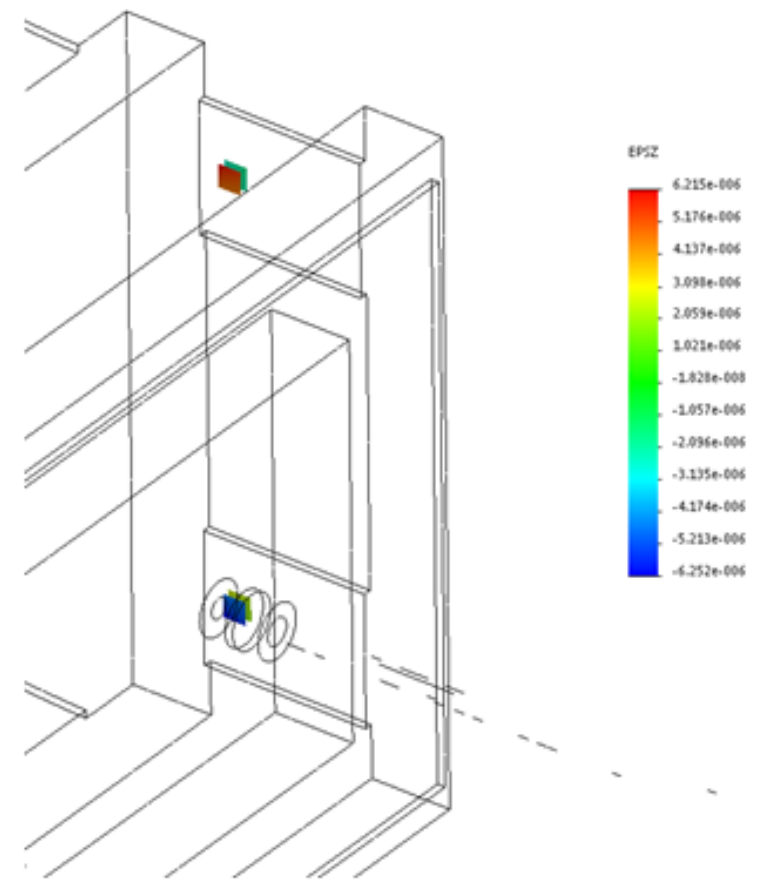

Fig. 13 Strains on the sensors for resistance force measuring emerged after only lift force loading the balance

One can quickly notice the order of magnitude of these strains that is ten times lower than the one corresponding to the lift, as well as the fact that the value of the strain on the upper side (in this case the left side) is positive, whereas on the lower side it is negative.

The values of the sensor's strain corresponding to this vertical composite strip are a little apart due to the asymmetric loading of the balance (the tubes not being contained in the symmetry plane of the sensor), and therefore this type of force application would generate the bending and twisting of the balance.

The determination the lift generated moment is characterized by a linear variation with the distance to the application of the force, fact theoretically and experimentally determined. Figure 14 presents the experimental variation of the lift generated a moment that was measured at the same time as the lift. Remarkable is the lowering intensity of the bending moment with the decreasing distance between the edge of the frame and the point of force application. This distance was decreased successively by $2.5 \mathrm{~mm}$ starting from the edge of the tube.

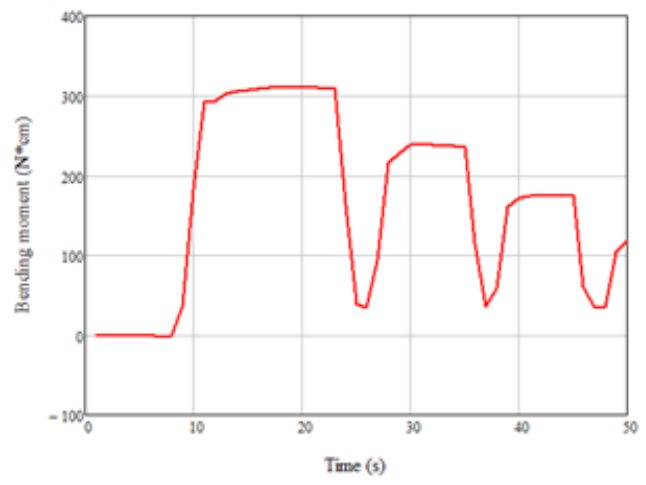

Fig. 14 Bending moment variation with the lowering of force application distance to the frame's edge

The fiberglass structures are recommended to be used for various high performance fields [17-20].

The research is valuable starting from the fact that the developed model allows further testing of various composite fiberglass materials including the recyclable 
wasted plastics, scattered in huge amounts around us [ 21, 22]. Thus, it would be increased the wellbeing and health of all individuals [23] and it would be reduced the environment burden $[24,25]$.

\section{Conclusions}

A three-component balance has been designed, analyzed and manufactured in the Military Technical Academy. Being a multi-piece type, it employs the use of six custom-made load cells (sensors) to transfer the aerodynamic forces and moments from the wing to the computer software environment. The relations between the loads acting on the wing model and the measured forces are underlined.

The focus of the paper is on analyzing the placement of the strain gauge on the fiberglass composite laminate, as it is an important issue for increased sensor precision. A theoretical approach says that the strain gauge positioned right at the edge of the frame leads to the maximum strain value, therefore to the maximum sensor effectiveness. However, in this particular case, the numerical and also experimental studies contradict it somewhat by placing the strain gauge at a distance of $0.68 \mathrm{~mm}$ away.

The positioning of the force vector and its influence on the strain distribution over the lift sensor is also analyzed with the finite element method and experimentally validated using dead weight placement. A good behavior of the sensor can be seen and the measured value being insignificantly influenced by the force vector placement (under $1 \%$ ). Also remarkable and a statement for the decoupling of the forces and moments introduced by this balance is the profound influence one type of aerodynamic force(lift) loading, has on the resistance or moment sensors. This is ten times less by order of magnitude.

Another interesting conclusion is the lowering intensity of the bending moment with the decreasing distance between the edge of the frame and the point of force application, proving that distributing the load over the surface of the wing will not influence the sensor data.

Acknowledgements: The obtained results experimentally validated and presented here are part of the Ph.D. thesis entitled Contributions to the use of the air-flexible surfaces for micro- and mini-unmanned aircrafts for defense and security applications, by Ph.D. Student Eng. Radu Pahonie under the guidance of Prof. Ph.D. Eng. Cristian Barbu.

\section{References}

1.LIAN, Y., SHYY, W., VIERU, D., ZHANG B., Prog. AeroSp. Sci., 39, no. 6-7, 2003, p. 425.

2.AMADO, S, LARCO, C., PAHONIE, R., NICOLAESCU, I., Coupled Transient Analysis of a UAV Composite Wing, Proceedings of the 17th International Conference: Scientific Research and Education in the Air Force, AFASES 2015, ISSN 2247-3173, 2015.

3.SAMARDŽIÆE, M., ANASTASIJ EVIIE, Z., MARINKOVSKI, D., ÆEURÈIÆE, D., ISAKOVI/E, J., Sci. Tech. Rev., 64, no.3, 2014, p.40.

4.ROTARU, C., CIRCIU, I., EDU, R.I., Mathematical Model of Induced Flow on the Airplane Vertical Tail, ICNAAM-2015, AIP Conference Proceedings, 1738:1, http://doi.org/10.1063/1.4951802, p. 030046-1.
5.ROSU, P.V., MIHAILA-ANDRES, M., IONESCU, C., ADOCHIEI, F., Experimental and numerical evaluation of the retention force for metallic matrix attachment systems, 2013 E-HEALTH AND Bioengineering Conference (EHB), 4th IEEE International Conference on E-Health and Bioengineering (EHB), Iasi, Romania, Nov 21-23, 2013.

6.MOAVENI, S., Finite Element Analysis, 1st ed., Pearson Education, Prentice Hall, New Jersey, 1999.

7.KUROWSKI, P., Engineering Analysis with SolidWorks Simulation, 1st ed., SDC Publications, Mission, Kansas, 2012.

8.J ONES, R.M., Mechanics of Composite Materials, 2nd ed., Taylor \& Francis, Inc., Philadelphia, 1999, p. 187.

9.PILATO, L.A, MICHNO, M.J ., Advanced Composite Materials, Springer Verlag, Berlin-Heidelberg, 1994.

10.MAXFIELD, B., Engineering with Mathcad, 1st ed., ButterworthHeinemann, Oxford, 2006.

11.EDU (ADOCHIEI) I., GRIGORIE, T.L., ADOCHIEI, F., NEGREA, P., CRISTIAN, V., JULA, N., Assistive Inertial 3D Positioning MEMS System, 2015 E-Health and Bioengineering Conference (EHB), Iasi, Romania, Nov 19-21, 2015.

12.ANDRUSEAC, G.G., GRIGORIE, T.L., ADOCHIEl, F., ROTARU, C., PASARICA, A., COSTIN, H., ADOCHIEI, I., A Remote-Controlled Mobile Platform for Identifying Indoor Human in Risk Situations, 2015 EHealth and Bioengineering Conference (EHB), Iasi, Romania, Nov 1921, 2015.

13.BOLDUREANU, G., LACHE, C., BOLDUREANU, D., PADURARU, T., NICULESCU, N., Environ. Eng. Manag. J., 12, no. 11, 2013, p. 2071.

14.MUSTATA, S.M., MIHAILA-ANDRES, M., LARCO, C.M., CIRCIU, I., Mechanics to obtain multi-layer materials using the explosive welding method, Review of the Air Force Academy, 1, 2011, p. 17.

15.MUSTATA, S.M., MIHAILA-ANDRES, M., LARCO, C.M., CIRCIU, I., Special multi-layer materials obtaining using nonconventional methods, Proceedings of the Scientific Research \& Education in the Air Force-AFASES, 2011, p.923.

16.PADURARU, T., VATAMANESCU, E.M., ANDREI, A.G., PINZARU, F., ZBUCHEA, A., MAHA, L.G., BOLDUREANU, G., Environ. Eng. Manag. J., 15, no. 7, 2016, p.1635.

17.TOKAR, A., NEGOITESCU, A., ADAM, M., TOKAR, D., , Mat. Plast., 51, no. 4, 2014, p. 432.

18.BABIA, A., PARAUSANU, I., GHEORGHIU, H.M., Mat. Plast., 51, no. 1,2014, p. 67.

19.POPESCU, T.C., DUMITRESCU, C., BORDEASU, I., Mat. Plast., 53, no. 1,2016, p. 174.

20.ZECHERU, G., DUMITRESCU, A., DRAGHICI, C., YUKHYMETS, P., Mat. Plast., 53, no. 2, 2016, p. 252.

21.COSTULEANU, C.L., VINTU, C.R., ROBU, D.A., IGNAT, G., BREZULEANU, S., Rev. Chim. (Bucharest), 66, no. 5, 2015, p. 743.

22.COSTULEANU, C.L., BOBITAN, N., DUMITRESCU, D., Environ. Eng. Manag. J., 14, no. 6, 2015, p. 1423.

23.COSTULEANU, C.L., DUMITRESCU, D., BREZULEANU, S., BOBITAN, N., Rev. Cercet. Interv. Soc., 48, 2015, p.50.

24.COSTULEANU, C.L., BREZULEANU S., IGNAT, G., BOLDUREANU, G., TOMA, M.C., ANDRUSEAC, G.G., Rev. Chim. (Bucharest), 67, no. 10, 2016, p. 1990.

25.IGNAT, G., COLIBABA, C., COSTULEANU, C.L., BALAN, A., ROTARU, L., SANDU, I.C.A., Mat. Plast., 53, no. 3, 2016, p. 367

Manuscript received: 2.12 .2016 